\title{
Assessing the Perceptions and Preferences between Online and In-Person Classroom Learning among University Students in Rwanda
}

\author{
Gloria Nishimwe1 ${ }^{*}$, Sam Kamali1 ${ }^{1}$ Eden Gatesi1, Rex Wong2,3 \\ ${ }^{1}$ School of Medicine, University of Global Health Equity, Butaro, Rwanda \\ ${ }^{2}$ Bill and Joyce Cummings Institute of Global Health, University of Global Health Equity, Butaro, Rwanda \\ ${ }^{3}$ School of Public Health, Yale University, New Haven, USA \\ Email: *gloria.nishimwe@student.ughe.org
}

How to cite this paper: Nishimwe, G. Kamali, S., Gatesi, E., \& Wong, R. (2022). Assessing the Perceptions and Preferences between Online and In-Person Classroom Learning among University Students in Rwanda. Journal of Service Science and Management, 15, 23-34.

https://doi.org/10.4236/jssm.2022.151003

Received: January 20, 2022

Accepted: February 18, 2022

Published: February 21, 2022

Copyright $\odot 2022$ by author(s) and Scientific Research Publishing Inc. This work is licensed under the Creative Commons Attribution International License (CC BY 4.0).

http://creativecommons.org/licenses/by/4.0/ (c) (i) Open Access

\begin{abstract}
The COVID-19 pandemic has resulted in many schools rapidly rolled out online learning due to school closure or lockdown. This study assessed the online learning experience of 193 students in different universities of Rwanda during COVID-19. The reported main advantages of online learning revolved around the comfortability and self-responsibility in their studies. However, internet access and stability remained the biggest challenges. Respondents reported online learning not stimulating, lacked interactions with other students and with instructors, and they were distracted easily and had difficulty to maintain their discipline. Many students indicated they prefer in-person classes over online learning. Investment to provide students stable internet access and to training instructors to design more interactive and engaging online learning materials according to best practices could improve the students' online experience. The use of blended online and in-person classroom learning to maximize students learning experiences and outcomes should be explored.
\end{abstract}

\section{Keywords}

Online Learning, Higher Education, Rwanda, Students, Covid-19

\section{Introduction}

Since first discovered in December 2019, the Sars-CoV-2 Coronavirus has spread around the globe and has caused many school closures temporarily (WHO, 2020)—inevitably disrupted learning. Many schools have resorted to delivering teaching via online platforms. 
Globally, e-learning has grown over the past several years as technology advances and the internet becomes more available (Brandon Hall Group, 2003; O’Neill, Singh, \& O'Donoghue, 2004; Biel \& Brame, 2016; Allen \& Seaman, 2017). In 2014, over 5.8 million students participated in online classrooms either via asynchronously (learners studying the materials completely at their own time) or synchronous (learners meet in real time via an online platform) (Ryan, 2001; Allen \& Seaman, 2016). While online learning offers flexibility, convenience for both instructors and students in timing and location, and has the potential to reach students with limited access to higher education due to socioeconomic, financial, educational, and personal reasons (Davis, 2000; Hara \& Kling, 2000; Haugen et al., 2001; Liaw \& Huang, 2002; Chen et al., 2010; Flowers et al., 2012; Hansen \& Reich, 2015; Willging \& Johnson, 2009; Biel \& Brame, 2016; Seaman et al., 2018), studies have shown some online delivery formats that could diminish the student experience, impair the ability of students to connect with faculty, decrease instructional quality, and minimize instructor-learner interactions (Hara \& Kling, 2000; Laine, 2003). Students may also feel isolation, frustration, anxiety, and confusion (Hara \& Kling, 2000; Piccoli, Ahmad, \& Ives, 2001). E-learning also requires learners to have greater discipline and self-motivation to make a time commitment to learning; higher student attrition rates were commonly found in online learning (Frankola, 2001; Laine, 2003; Ryan, 2001; Golladay, Prybutok, \& Huff, 2000; Serwatka, 2003). Large scale study in the USA did not show if online learning is superior as a medium compared to face-to-face classes (Means, Toyama, Murphy, Bakia, \& Jones, 2010).

Although e-learning has been growing rapidly globally, it remains at an early stage of development in most African countries, largely due to insufficient infrastructure, connectivity, and materials (Koohang \& Durante, 2003; Harerimana \& Mtshali, 2017; Harerimana \& Mtshali, 2018; Ndayambaje, 2014). During the current pandemic, many schools rapidly rolled out online learning due to school lockdown, understanding on how students perceived and reacted to e-learning was necessary, yet was not conducted before. Accordingly, this study was conducted to assess how students compare the learning platforms and to understand the challenges they faced. An online survey was conducted to collect university students' perception on their online learning experiences. The results of the study can inform future design of effective and appropriate e-learning programs in Rwanda.

\section{Materials and Methods}

\subsection{Setting}

Rwanda has a population of about 12 million people, with about 4 million (40\%) within the age of 16 to 30 years (National Institute of Statistics of Rwanda, 2015). As of 2018, there were 89,160 students enrolled in 40 higher education institutions (Rwanda Ministry of Education, 2018). 


\subsection{Design and Sample}

The study utilized a non-probability sampling method. An online survey was sent to students who were 18 years old or above, were enrolled in academic programs in universities in Rwanda and had taken online courses in Rwanda from February to April 2021. The recipients were encouraged to share the link to other people who fulfilled the selection criteria.

\subsection{Data Collection Tool and Method}

The survey tool was developed based on the Course Experience Questionnaire (CEQ) and some other similar questionnaires used in other studies (Smart \& Cappel, 2006; Wang \& Liu, 2019; Gurpinar, Alimoglu, Mamakli, \& Aktekin, 2010). There were three parts in the survey. Part 1 included five demographic information. Part 2 contained 17 statements related to the participants' perceptions and experience related to online compared to in-person learning. Respondents could choose one of the five options for each statement on a five-point $\mathrm{Li}$ kert scale: "strongly disagree", "disagree", "neither agree or disagree", "agree" and "strongly agree". Two open-ended questions were included in part 3 to ask respondents to provide the challenges they faced in online learning and other comments. The survey was developed and offered in English, and it took about 10 minutes to complete. The first page of the survey included the information of the study and a statement of consent. Participants were required to fill the checkbox, which served as a proxy for written consent. The study was approved by the University of Global Health Equity Institutional Review Board.

\subsection{Measures}

The key measures of the study were the percentages of strongly agreed/agreed and strongly disagreed/disagreed with each of the statements.

\subsection{Data Management and Analysis}

Data collected from the online survey were downloaded to excel format. It was cleaned and coded before being uploaded to SPSS for analysis. Descriptive statistics were used to summarize the demographic data and the key measures. One sample binomial proportion tests were used to detect differences between the proportion of strongly agree/agree and strongly disagree/disagree answers for each statement on their perception about online versus in-person learning. All quantitative data analyses were conducted using SPSS v.26, with the P-value set at 0.05 . Content analysis was conducted to summarize the themes from the two open-ended questions.

\section{Results}

A total 193 people attempted to complete the survey, three were removed since they did not answer any of the questions. The final sample contained 190 samples. The average age was 21.9 years old, with 161 (87.5\%) of them 25 years old 
or younger. Among all the respondents, 110 (57.9\%) were female, 168 (88.4\%) were in undergraduate programs, about half $(\mathrm{n}=91,49.5 \%)$ had never taken online courses before COVID-19, and the majority of them were taking synchronized $(\mathrm{n}=106,56.4 \%)$ or combination of synchronized and asynchronized courses $(n=45,23.9 \%)$ (Table 1$)$.

There was no statistical significance detected between the percentages of respondents who agreed/strongly agreed and those who disagreed/strongly disagreed on seven statements: 1) 46.6\% agreed/strongly agreed "I can understand the content better in online learning" versus $53.4 \%$ disagreed/strongly disagreed $(P=0.488) ; 2) 45.5 \%$ agreed/strongly agreed "I need less time and effort to learn the same amount of material in online learning" versus $54.5 \%$ disagreed/strongly disagreed $(P=0.316) ; 3) 46.5 \%$ agreed/strongly agreed "Online classes improve my communication skills" versus $53.5 \%$ disagreed/strongly disagreed ( $P=0.45)$; 4) $46.9 \%$ agreed/strongly agreed "I receive sufficient feedback from instructor in online courses" versus $53.1 \%$ disagreed/strongly disagreed $(P=0.51)$; 5) $53.4 \%$ agreed/strongly agreed "Online courses develop my ability as team player" versus $46.6 \%$ disagreed/strongly disagreed $(P=0.456) ; 6) 55.1 \%$ agreed/strongly agreed "Online courses encourage me to value perspectives other than my own" versus $44.9 \%$ disagreed/strongly disagreed $(P=0.268)$; and 7) $47.1 \%$ agreed/ strongly agreed "I can easily ask questions when I don't understand" versus $52.9 \%$ disagreed/strongly disagreed ( $P=0.551$ ) (Table 2).

Significantly more respondents agreed/strongly agreed on the following three statements: 1) "I am more relaxed and comfortable in online classes" $(62.4 \%, P=$ $0.003)$; 2 " "Online courses develop my ability to plan my own work" $(78.1 \%, P<$ $0.001)$; and 3) "Online courses develop my confidence to investigate new ideas" (67.6\%, $P<0.001$ ) (Table 2).

Table 1. Table summarizing the sample demographic information.

\begin{tabular}{ccc}
\hline \multirow{2}{*}{ Sample } & N (\%) \\
\cline { 3 - 3 } Age & Mean (SD) & 190 \\
\hline \multirow{2}{*}{ Gender } & 25 or younger & $161(87.5 \%)$ \\
& Older than 25 & $23(12.5 \%)$ \\
\hline \multirow{2}{*}{ Education level } & Female & $110(57.9 \%)$ \\
\hline \multirow{2}{*}{ Online learning before COVID-19 } & Male & $80(42.1 \%)$ \\
\hline \multirow{2}{*}{ Type of online } & Undergraduate & $168(88.4 \%)$ \\
& Graduate & $22(11.6 \%)$ \\
\hline & No & $91(49.5 \%)$ \\
& Ysynchronized & $37(19.7 \%)$ \\
& Synchronized & $106(56.4 \%)$ \\
\hline
\end{tabular}


Table 2. Table summarizing the results on online versus face-to-face learning experiences.

\begin{tabular}{|c|c|c|c|c|}
\hline & & (Strongly) dis & (Strongly) agree & $p$-value \\
\hline 1 & I can understand the content better in online learning & $71(53.4 \%)$ & $62(46.6 \%)$ & 0.488 \\
\hline 2 & Online learning stimulates my interest more & $95(68.3 \%)$ & $44(31.7 \%)$ & $<0.001^{\star}$ \\
\hline 3 & $\begin{array}{l}\text { I need less time and effort to learn the same amount of material in online } \\
\text { learning }\end{array}$ & $78(54.5 \%)$ & $65(45.5 \%)$ & 0.316 \\
\hline 4 & Student discussion is better in online learning & $134(78.8 \%)$ & $36(21.2 \%)$ & $<0.001^{*}$ \\
\hline 5 & Student presentation as part of learning is better in online learning & $111(71.6 \%)$ & $44(28.4 \%)$ & $<0.001^{\star}$ \\
\hline 6 & Teacher-student interaction is better in online learning & $125(78.1 \%)$ & $35(21.9 \%)$ & $<0.001^{\star}$ \\
\hline 7 & I am more relaxed and comfortable in online classes & $56(37.6 \%)$ & $93(62.4 \%)$ & $0.003^{\star}$ \\
\hline 8 & Online classes help me to prepare my exam better & $98(71.5 \%)$ & $39(28.5 \%)$ & $<0.001^{*}$ \\
\hline 9 & Online classes improve my communication skills & $76(53.5 \%)$ & $66(46.5 \%)$ & 0.450 \\
\hline 10 & I receive sufficient feedback from instructor in online courses & $78(53.1 \%)$ & $69(46.9 \%)$ & 0.510 \\
\hline 11 & Online courses develop my ability as team player & $68(46.6 \%)$ & $78(53.4 \%)$ & 0.456 \\
\hline 12 & Online courses develop my ability to plan my own work & $32(21.9 \%)$ & $114(78.1 \%)$ & $<0.001^{\star}$ \\
\hline 13 & Online courses develop my confidence to investigate new ideas & $45(32.4 \%)$ & $94(67.6 \%)$ & $<0.001^{*}$ \\
\hline 14 & Online courses encourage me to value perspectives other than my own & $62(44.9 \%)$ & $76(55.1 \%)$ & 0.268 \\
\hline 15 & I can easily ask questions when I don't understand & $73(52.9 \%)$ & $65(47.1 \%)$ & 0.551 \\
\hline 16 & I retain information better from taking online course & $107(77 \%)$ & $32(23 \%)$ & $<0.001^{\star}$ \\
\hline 17 & Online courses help me to maintain my discipline in studying & $97(65.5 \%)$ & $51(34.5 \%)$ & $<0.001^{*}$ \\
\hline
\end{tabular}

* Significant at $P=0.05$.

Significantly more respondents disagreed/strongly disagreed on the following seven statements: 1) "online learning stimulates my interest more" (68.3\%); 2) "Student discussion is better in online learning" (78.8\%); 3) "Student presentation as part of learning is better in online learning" $(71.6 \%) ; 4$,$) "Teacher-stu-$ dent interaction is better in online learning" (78.1\%); 5) "Online classes help me to prepare my exam better" (71.5\%); 6) "I retain information better from taking online course" (77\%); and 7) "Online courses help me to maintain my discipline in studying” (65.5\%), all with $P<0.001$ (Table 2).

\section{Analysis of Open-Ended Questions}

A total 179 comments and challenges were received through the two open-ended questions. Four main themes were identified:

Theme 1. Internet connectivity was the biggest challenge during online learning.

Among all the comments, $84(46.9 \%)$ were related to slow internet connection, which inevitably affected their online learning experience.

"Connectivity issues make the experience less worthwhile" (26 years old, male, master).

"Online classes are conducted on the assumption that all students have a good 
and strong internet connection, which is not true and as a result some students are left behind." (20 years old, female, undergraduate)

Theme 2. Students found online learning lacked personal interactions.

Over $29 \%$ of the comments were related to students experiencing challenges in following or understanding the online instructions. When they had questions, they also found it difficult to ask questions.

"Sometimes you don't gain more clarification about the course while studying online but face to face really help, because when studying the instructor make more examples for us to understand well the course and we are free to even ask for any question, which is totally different from online classes by online classes sometimes there is also network issues and you find that you are not even able to access the course." (21 years old, female, undergraduate)

"Generally, challenges are related to not being able to ask all questions for clarification. Also, about virtual discussion among." (20 years old, female, undergraduate)

Theme 3. Students found it difficult to concentrate on online instructions.

About $20 \%$ of respondents mentioned that they were distracted during online instructions. They were less concentrated or motivated in taking online classes compared to in-person face-to-face lessons.

"Generally, challenges are related to not being able to ask all questions for clarification...also challenges in virtual discussion among." (19 years old female, undergraduate)

"Home distractions also affected my studies during online learning." (19 years old, male, undergraduate)

Theme 4. Respondents preferred in-person classes over online courses.

Over $30 \%$ of respondents mentioned that they preferred in-person classes.

"The face-to-face learning is way much better than the online classes." (21 years old, female, undergraduate)

"Sometimes you don't gain more clarification about the course while studying online but face to face really help, because when studying the instructor make more examples for us to understand well the course and we are free to even ask for any question, which is totally different from online classes by online classes sometimes there is also network issues and you find that you are not even able to access the course." (21 years old, female, undergraduate)

\section{Discussion}

During the 2020 COVID pandemic, schools in Rwanda had resorted to delivering classes online. The social distancing restrictions during the COVID pandemic had highlighted the previously documented advantages of online learning being flexible in learning location compared to in-person classes (Sinclair, Kabke, \& Jones, 2015; Carrard, Martins, Molina-Bastos, \& Gonçalves, 2017; Goffard, Odou, Aliouat-Denis et al., 2019). However, being able to deliver the classes is only one aspect of teaching and learning. Our study intended to assess 
the online learning experience of students in Rwanda. The results of our study showed there was no significant difference in understanding the contents through learning online versus in-person. Similarly, they reported they spent about the same amount of time and effort in studying whether it was taking online or in-person classes. Previous studies have also drawn inconclusive results on the effectiveness of online compared to in-person classes (Means, Toyama, Murphy, Bakia, \& Jones, 2010; Furió, Juan, Seguí, \& Vivó, 2015; Bavaresco et al., 2019; Biel \& Brame, 2016).

However, statistically more respondents have reported that they were more relaxed and comfortable in online classes. Naturally, in online courses, students took the classes at the locations of their own choices. That generally means a more comfortable and relaxed environment. Students also reported that online learning could help them to develop their ability to plan their own work, and to improve their confidence in investigating new ideas. In general, academic success relies on students' motivation to acquire new skills (Jacobs \& Newstead, 2000). Study had shown allowing students to work at their own pace could enhance their motivation to learn (Goffard et al., 2019). Online learning to a larger extent has less instructor-student and student-student interactions, such a learning environment pushes students to take on more initiatives to learn and investigate on their own. As stated in early research, motivation is a key factor in promoting life-long learning (McCombs, 1991) and computer literacy is a main competency in learning in the 21st century (Kozma, 2003), online learning may have the potential to promote students' ability to become life-long learners. Further studies in this area could be conducted in the future.

Despite the benefits of online learning, our results also showed a significant percentage of respondents found online learning was not stimulating and found themselves easily distracted. Online classes can be in many different formats, including synchronized video conferencing, to pre-recorded asynchronized instructional videos, text-based chat, and threaded discussion (Newberry, 2001). Studies have suggested many best practices that can reduce distractions, including using shorter videos to avoid overload, organizing words and pictures, and combining narration with animation simultaneously as visual cues to highlight essential information (Goffard et al., 2019; Mayer \& Fiorella, 2014). Studies have also found students tend to react more positively to some video styles. Lecture slides with illustrations and animations that visualized content were better received by students compared to those with many texts and no illustrations (Choe, Scuric, \& Eshkol et al., 2019; Kirkwood \& Price, 2014; Morton et al., 2016). These principles should be followed when producing online resources even though this may require more effort in production.

Many of our respondents also reported they had difficulties in student discussion, presentation, teacher-student interactions, exam preparation, information retention and maintaining their discipline in studying. By nature, online classes do not have in-person interactions between participants, some studies 
have shown students rarely using online forums like discussion boards to interact with other students or with the lecturer (van Doorn \& van Doorn, 2014) and that poses certain challenges to some learning activities. Many studies have shown some class activities including debates, group presentations, practical were much better conducted in face-to-face settings (Moule, Ward, \& Lockyer, 2010; Howlett et al., 2011; Edginton \& Holbrook, 2010; Beale, Tarwater, \& Lee, 2014). Studies have shown that most students not only liked the classroom face to face interactions, but also found such activities increased their level of enthusiasm for independent working (Peine, Kabino, \& Spreckelsen, 2016; Woltering, Herrler, Spitzer, \& Spreckelsen, 2009). Studies have also shown in-person classes were superior in providing immediate feedback and tailored messages, detecting visual cues via body language, and relaying communicator feelings or emotions (Newberry, 2001). Our study results were consistent with some of these previous findings.

Probably the most obvious questions about online learning are access to and use of information technology. In this study, the most frequently reported challenges during their online learning experience were internet access and stability. Network infrastructure is one of the three main elements in implementing e-learning, alongside information and communication technology knowledge and content development (Aung \& Khaing, 2015). According to the World Bank, only $22 \%$ of the population in Rwanda have access to the internet (The World Bank Data, 2019). Similar to other studies, most students in our study found it difficult to do online courses when having limited access to a stable internet (Cabual \& Cabual, 2022). As e-learning is becoming a global trend, the Rwanda government as well as the education sector need to invest and be equipped in this basic yet essential infrastructure to allow a full experience of virtual class. As the COVID-19 pandemic persists, it is inevitable that some online teaching and learning will continue. Schools creating e-learning departments can help train instructors on how to use digital communication strategies, develop online educational materials to positively impact online learning experience.

For half of our participants of the study (49.5\%), this was their first experience doing online learning, and many respondents indicated that they preferred in-person over online classes. Our results provided some initial insights on how students perceive online learning. However, the results of this study must be viewed considering some limitations. One, due to Covid pandemic, our study was conducted via an online survey, we could not avoid selection bias, and the sample size may not be generalizable to the entire student population. Students who did not have internet access to partake in online classes would be unlikely to participate in our survey. Two, the type of online learning during Covid lockdown were mostly synchronous (over $80 \%$ ), presumably via zoom or other different online meeting platforms. Our study did not investigate the learning experience on the different types of e-learning formats. Future research in this 
area may help design the best and context-specific online learning approach.

\section{Conclusion}

This study assessed the online learning experience of 193 students in different universities of Rwanda during COVID-19. The main advantages of online learning reported by the responses revolved around the comfortability and self-responsibility in their studies. However, internet access and stability remained the biggest challenges. While some reported e-learning promoted their ability to organize their own work, effort to promote student-student and student-instructor interaction is needed. Investment to provide students stable internet access and to training instructors to design more interactive and engaging online learning materials according to best practices would help maximize the online learning benefits. While online courses may have some benefits, especially during the pandemic, some important in-class experiences including debates and practical were difficult to execute via online format. The use of blended online and in-person classroom learning to maximize students learning experiences and outcomes should be explored. The generalizability of the study may be limited due to the relatively sample size and potential selection bias. Future investigation on the method of online learning formats should be conducted to inform future program design.

\section{Acknowledgements}

The authors would like to thank all the participants in the study.

\section{Authors' Contributions}

G. Nishimwe, S. Kamali, E. Gatesi conceptualized the study. All authors conducted the literature review, study design, data collection, interpretation of data, drafting and editing the manuscript. All authors have seen and approved the final manuscript.

\section{Conflicts of Interest}

The authors declare no conflicts of interest regarding the publication of this paper.

\section{References}

Allen, I. E., \& Seaman, J. (2016). Online Report Card: Tracking Online Education in the United States. Babson Survey Research Group. Babson College, 231 Forest Street, Babson Park, MA 02457. https://files.eric.ed.gov/fulltext/ED572777.pdf

Allen, I. E., \& Seaman, J. (2017). Digital Compass Learning: Distance Education Enrollment Report 2017. Babson Survey Research Group. https://files.eric.ed.gov/fulltext/ED580868.pdf

Aung, T. N., \& Khaing, S. S. (2015). Challenges of Implementing e-Learning in Developing Countries: A Review. In T. Zin, J. W. Lin, J. S. Pan, P. Tin, \& M. Yokota (Eds.), International Conference on Genetic and Evolutionary Computing (pp. 405-411). Springer. https://doi.org/10.1007/978-3-319-23207-2 41 
Bavaresco, C. S., Braganca, S., de Paula Fries, F., Soria, G. S., De Moura, F. R. R., Rivaldo, E. G. et al. (2019). Satisfaction of Primary Healthcare Dentists after the Completion of a Distance Learning Course in Pediatric Dentistry. Iranian Journal of Public Health, 48, 1439-1444. https://doi.org/10.18502/ijph.v48i8.2982

Beale, E. G., Tarwater, P. M., \& Lee, V. H. (2014). A Retrospective Look at Replacing Face-to-Face Embryology Instruction with Online Lectures in a Human Anatomy Course. Anatomical Sciences Education, 7, 234-241. https://doi.org/10.1002/ase.1396

Biel, R., \& Brame, C. J. (2016). Traditional versus Online Biology Courses: Connecting Course Design and Student Learning in an Online Setting. Journal of Microbiology \& Biology Education, 17, 417-422.

Brandon Hall Group (2003). FAQs about e-Learning. https://www.brandonhall.com/public/faqs2/faqs2.htm

Cabual, R. A., \& Cabual, M. M. (2022). The Extent of the Challenges in Online Learning during the COVID-19 Pandemic. Open Access Library Journal, 9, 1-13.

Carrard, V. C., Martins, M. A., Molina-Bastos, C. G., \& Gonçalves, M. R. (2017). WhatsApp: A Telemedicine Platform for Facilitating Remote Oral Medicine Consultation and Improving Clinical Examinations-Some Considerations. Oral Surgery, Oral Medicine, Oral Pathology and Oral Radiology, 123, 408.

https://doi.org/10.1016/j.0ooo.2016.09.228

Chen, P. S. D., Lambert, A. D., \& Guidry, K. R. (2010). Engaging Online Learners: The Impact of Web-Based Learning Technology on College Student Engagement. Computers \& Education, 54, 1222-1232. https://doi.org/10.1016/j.compedu.2009.11.008

Choe, R. C., Scuric, Z., Eshkol, E., Cruser, S., Arndt, A., Cox, R. et al. (2019). Student Satisfaction and Learning Outcomes in Asynchronous Online Lecture Videos. CBE-Life Sciences Education, 18, ar55. https://doi.org/10.1187/cbe.18-08-0171

Davis, J. H. (2000). Traditional vs. Online Learning: It's Not an Either/or Proposition. Employment Relations Today, 27, 47-60.

Edginton, A., \& Holbrook, J. (2010). A Blended Learning Approach to Teaching Basic Pharmacokinetics and the Significance of Face-to-Face Interaction. American Journal of Pharmaceutical Education, 74, 88. https://doi.org/10.5688/aj740588

Flowers, L. O., White, E. N., Raynor, J. E., \& Bhattacharya, S. (2012). African American Students' Participation in Online Distance Education in STEM Disciplines. SAGE Open, 2, Article ID: 2158244012443544. https://doi.org/10.1177/2158244012443544

Frankola, K. (2001). Why Online Learners Drop out. Workforce, 10, 52-60.

Furió, D., Juan, M. C., Seguí, I., \& Vivó, R. (2015). Mobile Learning vs. Traditional Classroom Lessons: A Comparative Study. Journal of Computer Assisted Learning, 31, 189201. https://doi.org/10.1111/jcal.12071

Goffard, A., Odou, P., Aliouat-Denis, C. M., Carnoy, C., Décaudin, B., Damien, C. et al. (2019). Development and Evaluation of a Hybrid Course in Clinical Virology at a Faculty of Pharmacy in Lille, France. JMIR Medical Education, 5, e10766.

Golladay, R., Prybutok, V., \& Huff, R. (2000). Critical Success Factors for the Online Learner. Journal of Computer Information Systems, 40, 69-71.

Gurpinar, E., Alimoglu, M. K., Mamakli, S., \& Aktekin, M. (2010). Can Learning Style Predict Student Satisfaction with Different Instruction Methods and Academic Achievement in Medical Education? Advances in Physiology Education, 34, 192-196. https://doi.org/10.1152/advan.00075.2010

Hansen, J. D., \& Reich, J. (2015). Democratizing Education? Examining Access and Usage Patterns in Massive Open Online Courses. Science, 350, 1245-1248.

https://doi.org/10.1126/science.aab3782 
Hara, N., \& Kling, R. (2000). Students' Distress with a Web-Based Distance Education Course: An Ethnographic Study of Participants' Experiences. Information, Communication and Society, 3, 557-579.

Harerimana, A., \& Mtshali, N. G. (2017). Facilitation Strategies Used in e-Learning by Nurse Educators in Rwanda. Journal of Nursing Education and Practice, 8, 24-32.

Harerimana, A., \& Mtshali, N. G. (2018). Implementing e-Learning in Resource-Constrained Nursing Education Institutions in Rwanda. Research and Reviews: Journal of Nursing and Health Sciences, 4, 1-14.

Haugen, S., LaBarre, J., \& Melrose, J. (2001). Online Course Delivery: Issues and Challenges. Issues in Information Systems, 2, 127-131.

Howlett, D., Vincent, T., Watson, G., Owens, E., Webb, R., Gainsborough, N., Fairclough, J., Taylor, N., Miles, K., Cohen, J., \& Vincent, R. (2011). Blending Online Techniques with Traditional Face to Face Teaching Methods to Deliver Final Year Undergraduate Radiology Learning Content. European Journal of Radiology, 78, 334-341. https://doi.org/10.1016/j.ejrad.2009.07.028

Jacobs, P. A., \& Newstead, S. E. (2000). The Nature and Development of Student Motivation. British Journal of Educational Psychology, 70, 243-254.

https://doi.org/10.1348/000709900158119

Kirkwood, A., \& Price, L. (2014). Technology-Enhanced Learning and Teaching in Higher Education: What Is "Enhanced" and How Do We Know? A critical Literature Review. Learning, Media and Technology, 39, 6-36.

Koohang, A., \& Durante, A. (2003). Learners' Perceptions toward the Web-Based Distance Learning Activities/Assignments Portion of an Undergraduate Hybrid Instructional Model. Journal of Informational Technology Education, 2, 105-113. http://jite.org/documents/Vol2/v2p105-113-78.pdf

Kozma, R. (2003). Technology, Innovation, and Educational Change: A Global Perspective. Eugene: ISTE.

Laine, L. (2003). Is e-Learning Effective for IT Training? $T+D$, 57, 55-60.

Liaw, S. S., \& Huang, H. M. (2002). How Web Technology Can Facilitate Learning. Information Systems Management, 19, 56-61.

Mayer, R. E., \& Fiorella, L. (2014). 12 Principles for Reducing Extraneous Processing in Multimedia Learning: Coherence, Signaling, Redundancy, Spatial Contiguity, and Temporal Contiguity Principles. In R. E. Mayer (Ed.), The Cambridge Handbook of Multimedia Learning (Vol. 279, pp. 279-315). Cambridge University Press.

McCombs, B. L. (1991). Motivation and Lifelong Learning. Educational Psychologist, 26, 117-127.

Means, B., Toyama, Y., Murphy, R., Bakia, M., \& Jones, K. (2010). Evaluation of Evidence-Based Practices in Online Learning: A Meta-Analysis and Review of Online Learning Studies. Washington DC: US Department of Education.

Ministry of Education (Rwanda) (2018). Education Statistics. https://www.statistics.gov.rw/publication/2018-education-statistics-report

Morton, C. E., Saleh, S. N., Smith, S. F., Hemani, A., Ameen, A., Bennie, T. D., \& Toro-Troconis, M. (2016). Blended Learning: How Can We Optimize Undergraduate Student Engagement? BMC Medical Education, 16, Article No. 195. https://doi.org/10.1186/s12909-016-0716-Z

Moule, P., Ward, R., \& Lockyer, L. (2010). Nursing and Healthcare Students' Experiences and Use of e-Learning in Higher Education. Journal of Advanced Nursing, 66, 27852795. https://doi.org/10.1111/j.1365-2648.2010.05453.x 
National Institute of Statistics of Rwanda (NISR) [Rwanda], Ministry of Health (MOH) [Rwanda], \& ICF International (2015). Rwanda Demographic and Health Survey 201415. Rockville, MD: NISR, MOH, and ICF International.

Ndayambaje, I. (2014). Facing ICTs and e-Learning Environment: An Investigation from the Graduates Registered in the First Batch of E-Learners under PanAfrican Tele-Education Programs in Rwanda. Rwandan Journal of Education, 2, 61-69.

Newberry, B. (2001). Raising Student Social Presence in Online Classes. In W. Fowler, \& J. Hasebrook (Eds.), WebNet 2001: Proceedings of the World Conference on the WWW and Internet (pp. 905-910). Orlando, FL: Association for the Advancement of Computing in Education.

O’Neill, K., Singh, G., \& O’Donoghue, J. (2004). Implementing eLearning Programmes for Higher Education: A Review of the Literature. Journal of Informational Technology Education, 3, 313-323. http://jite.org/documents/Vol3/v3p313-323-131.pdf

Peine, A., Kabino, K., \& Spreckelsen, C. (2016). Self-Directed Learning Can Outperform Direct Instruction in the Course of a Modern German Medical Curriculum-Results of a Mixed Methods Trial. BMC Medical Education, 16, Article No. 158. https://doi.org/10.1186/s12909-016-0679-0

Piccoli, G., Ahmad, R., \& Ives, B. (2001). Web-Based Virtual Learning Environments: A Research Framework and a Preliminary Assessment of Effectiveness in Basic IT Skills Training. MIS Quarterly, 25, 401-426. https://doi.org/10.2307/3250989

Ryan, S. (2001). Is Online Learning Right for You? American Agent \& Broker, 73, 54-58.

Seaman, J. E., Allen, I. E., \& Seaman, J. (2018). Grade Increase: Tracking Distance Education in the United States. Oakland, CA: Babson Survey Research Group.

Serwatka, J. (2003). Assessment in Online CIS Courses. Journal of Computer Information Systems, 43, 16-20.

Sinclair, P., Kabke, A., \& Jones, T. L. (2015). The Effectiveness of Internet Based e-Learning on Clinical Behavior and Patient Outcomes: A Systematic Review Protocol. JBI Database of Systematic Reviews and Implementation Reports, 13, 52-64. https://doi.org/10.11124/jbisrir-2015-1919

Smart, K. L., \& Cappel, J. J. (2006). Students' Perceptions of Online Learning: A Comparative Study. Journal of Information Technology Education: Research, 5, 201-219.

The World Bank Data (2019). Individuals Using the Internet (\% of Population). https://data.worldbank.org/indicator/IT.NET.USER.ZS

van Doorn, J. R., \& van Doorn, J. D. (2014). The Quest for Knowledge Transfer Efficacy: Blended Teaching, Online and In-Class, with Consideration of Learning Typologies for Non-Traditional and Traditional Students. Frontiers in Psychology, 5, Article No. 324. https://doi.org/10.3389/fpsyg.2014.00324

Wang, R., \& Liu, C. Y. (2019). The Relation of Dental Students' Learning Styles to Their Satisfaction with Traditional and Inverted Classroom Models. BMC Medical Education, 19, Article No. 315. https://doi.org/10.1186/s12909-019-1749-x

WHO (2020). Advice for the Public. Coronavirus Disease (COVID-19). https://www.who.int/emergencies/diseases/novel-coronavirus-2019/advice-for-public

Willging, P. A., \& Johnson, S. D. (2009). Factors that Influence Students' Decision to Dropout of Online Courses. Journal of Asynchronous Learning Networks, 13, 115-127.

Woltering, V., Herrler, A., Spitzer, K., \& Spreckelsen, C. (2009). Blended Learning Positively Affects Students' Satisfaction and the Role of the Tutor in the Problem-Based Learning Process: Results of a Mixed-Method Evaluation. Advances in Health Sciences Education, 14, Article No. 725. https://doi.org/10.1007/s10459-009-9154-6 